\title{
A QUALITATIVE STUDY OF THE CHALLENGES FACED BY MATERIAL DESIGNERS WHEN DEVELOPING DIY-MATERIALS
}

\author{
Charlotte Asbjørn SÖRENSEN and Emma THYNI \\ School of Art and Communication (K3), Malmö University, Malmö, Sweden
}

\begin{abstract}
The recent academic literature on material practices within design has revealed the emergence of a new design discipline, DIY-materials or material design. Designers educated in DIY-materials and the Material Driven Design method, applied in design courses in major European universities are beginning to identify themselves as material designers. This paper presents a qualitative case study of the challenges faced by material designers and design students developing DIY-materials from the stage of a small sample with promising experiential qualities and technical properties, towards a more viable material. A comparative case study of twenty-eight material driven design projects and four explorative semi-structured interviews were conducted with designers. The result suggest: (a) that designers have a tendency to focus more on the experiential attributes and aesthetical qualities rather than the technical attributes in the early stages of material development, (b) projects that are situated in specific contexts or systems have a higher success rate, (c) bio-based DIY-materials are in general sensitive to moist and high temperatures, (d) a systematic approach during tinkering combined with analytic skills are crucial for the development of DIY-materials. In this paper we also build on our previous research, regarding the development of reflective material practices for design students in higher education. It is hoped that this research can contribute to the further development of material design as a new design discipline.
\end{abstract}

Keywords: DIY-materials, material driven design, experiential knowledge, material education; product design

\section{INTRODUCTION}

The recent academic literature on material practices within design has revealed the emergence of a new design discipline, Do-It-Yourself (DIY) materials or material design [1],[2],[3]. In this paper, we use the definition of DIY-materials as defined by Rognoli, Bianchini, Maffei, \& Karana [4], i.e. ' materials which are created through individual or collective self-production practices, often by techniques and processes of the designer's own invention. They can be totally new materials, modified, or further developed versions of existing materials. Designers educated in DIY-materials [5] and the Material Driven Design method [4], applied in design courses in European universities, e.g. TU Delft (NL), Politecnico di Milano (IT), Imperial College London (UK), Malmö University (SE), and University of Gävle (SE) are beginning to identify themselves as material designers. However, these designers and students are facing great challenges when trying to develop DIY-materials with promising experiential qualities and technical properties [6] into viable materials. There are numerous examples of DIYmaterials that reach the development stage of aesthetically pleasing result and less pleasing technical properties (if compared to engineered materials). These are often communicated through tempting images and storytelling on social media platforms. Unfortunately, few DIY-materials manage to reach the stage of viable materials with good sensorial qualities and sufficient technical properties. There are however a few examples of successful circular and sustainable materials originating from design projects, e.g. Terroir, Residue and Mestic. The Terroir project by the Danish designers Edvard \& Steenfatt [7] use local seaweed and recycled paper cooked into a mouldable pulp. The cork like composite is then used in a local craft production of furniture and lampshades. Swedish designer Hanna Carlsson developed a wood composite made of residual products from local furniture industry and meat industry [8], [9]. The residue material is moulded into double curved surfaces in furniture production replacing polymer-based composites and utilizing waste from the furniture and meat industry in the 
Residue-chair (Figure 1). Mestic was developed in a multi-disciplinary team, with designer Jalila Essaïdi in the Netherlands. The Mestic team found a way to turn manure from cows into bioplastics, not only tackling the excess excrement, but also providing a sustainable source of biomaterials [10].

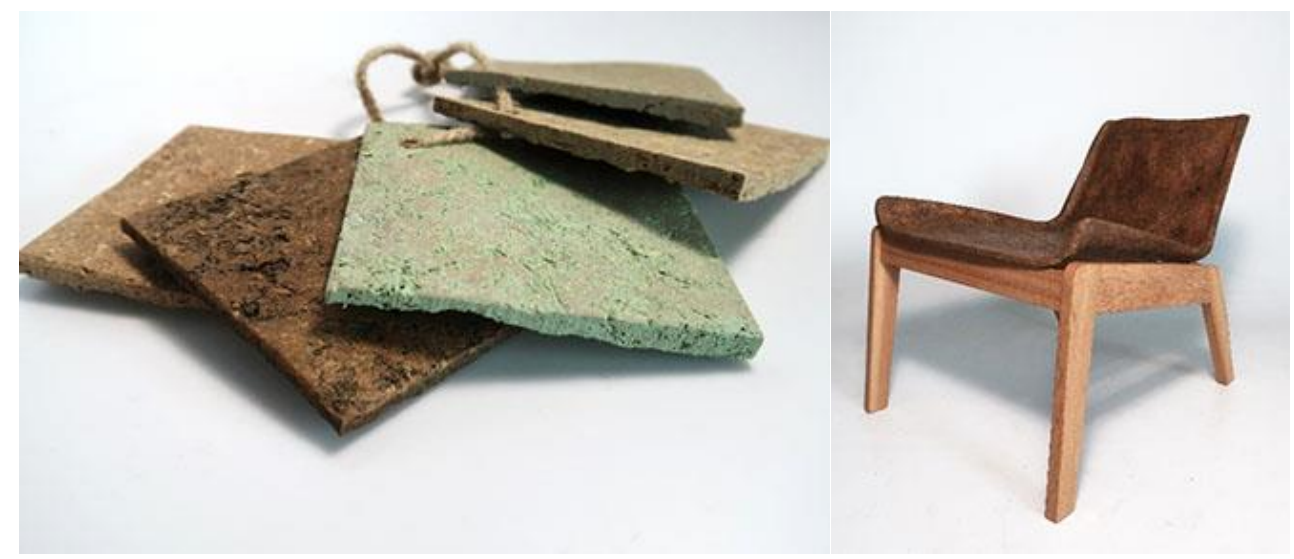

Figure 1. The Residue project by Hanna Carlsson (2019). Photo: H. Carlsson

In earlier research [6] the authors developed pedagogic framework for facilitating the development of reflective material practices in design education and developed pedagogic material for courses in DIYmaterials and Material Driven Design. This research has been the foundation for understanding the material driven design aspects and the processes of developing new bio-based materials. The intention of this pilot study is to explore (a) what the obstacles and challenges are for designers working with DIY-materials, (b) commonalities in design practice in relation to the development process of DIYmaterials and (c) the quality of the developed materials. All DIY-materials selected for this study are based on local waste streams, renewable resources and are bio-degradable.

\section{DIY-MATERIALS}

The democratization of personal fabrication technologies in parallel to the rising desire of individuals for personalizing their products offers opportunities to experiment with advanced, distributed and shared production processes as well as designing new materials [5]. Since most of our daily objects originates from industrial mass production, our material experiences, as users but also as designers, are affected and defined by industrial materials. (Industrial or engineered materials, refer to all materials that are industrially processed through a series of operations that transform industrial materials from a rawmaterial state into finished parts or products.) This industrial paradigm is established in society and will not radically change soon. However, there is an emergence of an alternative approach to product design in general and to materials from a design perspective. The design community have started to compose, combine, develop, modify, tinker and self-produce materials in a context that often focus on local waste streams. DIY-materials are being created through individual or collective self-production practices, often by techniques and processes of the designer's own invention [5]. These materials are often perceived as low-tech materials, with a crafty and imperfect appearance. Processes and techniques that come from disciplines, such as culinary science, arts and crafts, often creatively inspire the designers, activating a trans-disciplinary cross-pollination that often leads to original and poetic results. The alternative approach of DIY-practices brings a new dimension to the relationship between designer, technologies, processes and materials. The emergence of DIY-materials and practices contributes to the creation of new materials that offers opportunities for achieving new and unconventional materials experiences and sustainable alternatives [5]. Material experiments and explorations as part of a material practice has the potential to promote the transition of our linear industrial society towards circular and hopefully more sustainable processes [6]. The existing manufacturing processes and material classification systems are being challenged by these new design practices, e.g. distributed manufacturing and new materials that fall outside present classification systems. 


\section{COMPARATIVE CASE STUDY}

A comparative case study [11] of twenty-eight DIY-material projects were conducted. Common denominator for the selected projects are that all materials are (a) from renewable resources (b) biocompostable (c) based on local waste streams and that (d) designers initiated all projects, although industry was partially involved in some of the projects. The commonalities of the collected cases were then noted, as well as distinct differences. The gathered material was then analysed in a final comparative case study, see example in Figure 2. Each project was ranked individually by three researchers on a scale from 1-6 (1 being the lowest score and 6 the highest), each followed by a shortwritten motivation in ten different categories. The ten categories focused on i.e. how clear the context of the material is established, what stage of development the material is on, level of systematic approach and analysis, quality of the material vision, and level of processing techniques. The result from the comparative case study was used to design the interview guide for the qualitative case study.
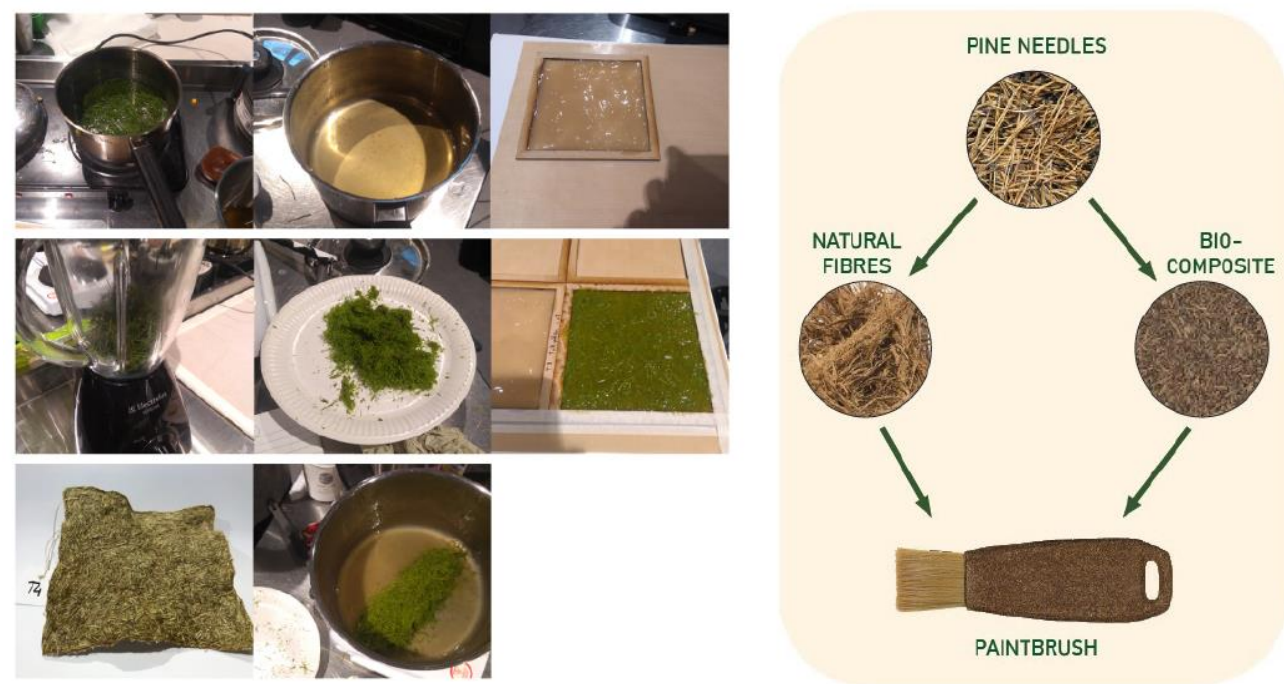

Figure 2. Pine needle material by Neriman Arif \& Jonas Hagbert (2020). Photo: Arif \& Hagman

\section{QUALITATIVE CASE STUDY}

The qualitative case study offers a richness that enables sophisticated understandings of how and why specific occurrences, processes, and constellations happen [12]. The aim of the qualitative case studies was to explore if commonalities in design practice could be found in relation to the development process of DIY-materials and the quality of the developed materials. The practice as a "nexus of doings and sayings' is not only understandable to the one who undertakes that practice, but is also understandable to potential observers, at least within the same culture. To gather the data, five qualitative interviews were conducted with designers. The five informants were selected based on the results from the comparative case study and constituted the highest ranked projects regarding quality of the process and final material. The informants received a short general introduction of the research background when scheduling the interview. Before each interview the interviewers had gone through the different MDDprojects documentation in detail. The interviews lasted from 47 minutes up to 76 minutes. The five interviews were recorded, transcribed, coded in NVivo with open coding, and then analysed using a cross-case comparison approach [11]. All the interviews were conducted and transcribed in Swedish. No translations were made before coding the data, instead the results were translated, to avoid losing important details in the data. The interviewers have experience of working with DIY-materials and Material Driven Design (MDD). This was helpful in conducting the interviews, being familiar with the vocabulary and the context, as one of the interviewees pointed out. This experience might also have a disadvantage, e.g. interviewees may hold back some information believing that it is common knowledge. The challenges were first to analyse the qualitative data and then to make analytical generalization of these findings. For this reason, the authors have chosen a practice theoretical perspective of Category Zooming [13]. Category Zooming is a way of generalizing by zooming in on aspects of the qualitative data material. This way of generalizing goes into depth with the details and complexities in one single 
point of the study. In our multiple comparative studies, comparison between cases were undertaken to ensure what was compared was analytically sufficiently identical across the cases. The main themes that recurred during the coding were:

- Intuition

- Analytical skills

- $\quad$ Strategies

- Theoretical knowledge

- $\quad$ Practical skills

- $\quad$ Reading/ understanding the material

- $\quad$ Equipment

- Communication

\section{FINDINGS}

The commonalities found in the result from the comparative case study suggest: (a) that designers have a tendency to focus more on the experiential qualities and aesthetical attributes rather than the technical properties in the early stages of material development, (b) projects that are situated in specific contexts or systems have a higher success rate, (c) bio-based DIY-materials are in general sensitive to moist and/ or high temperatures, (d) a systematic approach combined with theory and analytic skills are crucial for succeeding with the development of DIY-materials. When analysing the results of the coding in the qualitative case study, certain relationships became visible:

- choice of strategy was affected by level of theoretical knowledge, practical skills and the level of use of intuition

- the ability to read/ understand the material, directly related to the level of development of sensorial qualities, technical properties, context and future potential of application areas

- the ability to utilize theoretical knowledge, access to equipment and existing practical skills clearly influenced the quality of the developed processing process or the cultivation of the DIYmaterial

- $\quad$ communication of sensorial qualities, technical properties, possible area of application and context mainly focused on strengths, and scarcely on existing challenges

In the comparative case study, a pattern emerged indicating that the designers who chose to focus primarily on the aesthetical attributes and experiential qualities in the beginning of the process, later struggled with the development of viable technical properties. The designers that strategically developed sensorial qualities and technical properties simultaneously in the DIY-process all reached a higher level of results. The qualitative case study indicated that the analytical skills of the designer and the ability to develop strategies are crucial for simultaneous development. The interviewees also pointed towards the importance of being able to 'read the material' that is, intuitively understanding what happens when combining different ingredients or components in the material recipes. The more extensive preknowledge of the different ingredients, their functions and characteristics the designer have the better ability to fine-tune the material properties. This pre-knowledge the designers had gained equally from theory and practice. One interviewee pointed out the challenge of first finding information on e.g. the biological and chemical composition of a specific seaweed, then decipher the information and finally transform it into useful input when composing a new material. Another interviewee stressed the importance of developing craft skills and the ability to adapt techniques from different fields when processing the ingredients but also when shaping the final material. However, the greatest challenge faced by the designers was that most bio-based DIY-materials are sensitive to moist and/ or high temperatures in comparison to engineered polymers. Some of the projects addressed the problem by trying to improve the technical properties of the material and others had worked with surface treatments to protect the material. The surface treatment however, changed the tactile properties and visual qualities of the material. Projects that had a point of departure in a specific context (e.g. a specific waste stream) or system (e.g. furniture industry) kept a higher level of quality regarding viable technical properties and level of processing processes. In general, the context of these projects was clearly defined early in the process, and thereby could function as a guide in the decision-making process, Figure 3. 

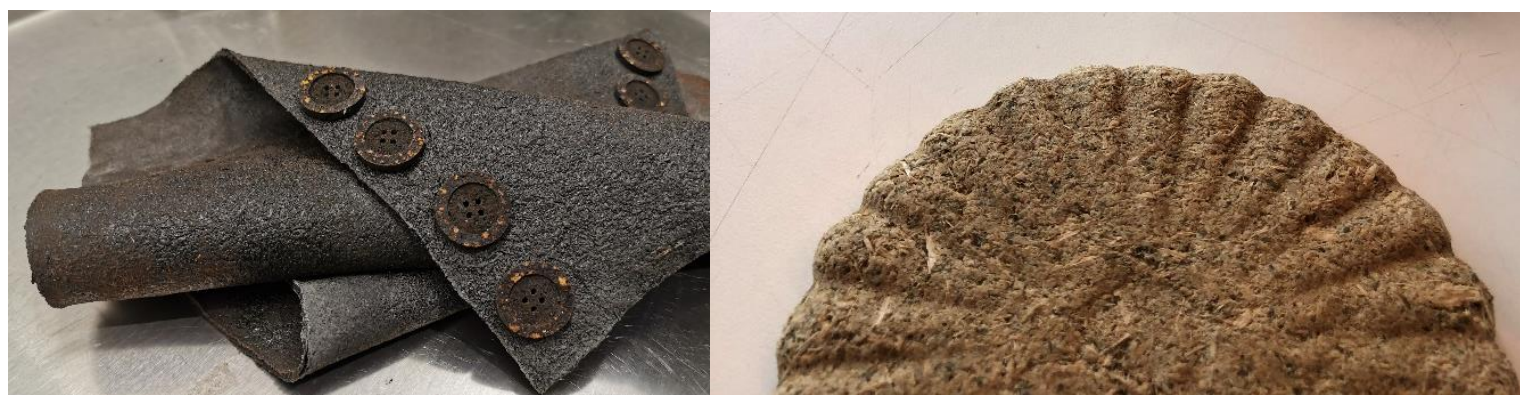

Figure 3. (a) Sealeather by Emma Thyni \& Enes Musa (2019) and (b) Roseboard by Therese Rosén \& Jonna Kytölä (2020). Photo: Author

Storytelling, pictures of the material and of the application area was preferred methods of communication to promote the sensorial qualities and environmental benefits, as for technical properties the lack of communication was in general apparent. As mentioned earlier, in all projects the bio-based materials shared the limitations of being sensitive to moist, compared to conventional polymers and composites. In some projects, the limitation had been turned into an advantage in the final application of the DIY-material, e.g. that the product could be dissolved in boiling water or become compost in the final stage of its life cycle, Figure 1b. These projects, all had in common that they had focused on both the sensorial qualities and the technical properties early in the process.

\section{FINAL REMARKS}

The DIY-materials in this study are produced by using local resources; they promote sustainability, are placed in a circular context and underlines the importance of the connection between a context, a community and the designer. When designers work with and creates new materials, they transfer meanings into the materials they develop for products, based on intentions and expected use, often communicated through the material, the object and storytelling. The most successful material designers strategically gathered knowledge both through literature, systematic material experiments and by using their network to find external expertise. Choice of strategy was clearly related to prior experience and the level the material designers of education. The results of this pilot study indicate a need for the development of strategies that can support the designer during the different stages of developing DIYmaterial samples into viable materials suitable for a craft based or small-scale manufacturing. We believe that DIY-materials can contribute to a societal change by offering sustainable and democratic ways of producing, using and re-using materials in society. The linear industrial processes of 'take, make, dispose' that have driven economic growth and shaped lifestyles over the last two centuries are being questioned and rethought. Material Driven Design and DIY-materials in combination with theoretical framework from circular design and sustainable development can provide entry points to address parts of the complexity and envision new alternative solutions. We firmly believe that there is a need for a diversity of solutions on our journey towards a sustainable future.

\section{REFERENCES}

[1] Mariani I. and Rampino L. (eds). Advancements in Design Research. 11 PhD Theses on Design as we do in Polimi, 2019 (Franco Angeli, Milano).

[2] Rognoli V., Bianchini M., Maffei S. and Karana E. DIY materials. Materials \& Design, 2015, 86, 692-702.

[3] Rognoli V. and Ayala Garcia C. Material activism. New hybrid scenarios between design and technology. Cuadernos del Centro de Estudios en Diseño y Comunicación.Ensayos, 2018, 70, 13.

[4] Rognoli V., Bianchini M., Maffei S. and Karana E. DIY materials. Materials \& Design, 2015, 86, 692-702.

[5] Rognoli V. and Ayala Garcia C. The material experiences as DIY-Materials: Self production of wool filled starch-based composite (NeWool). In Making futures, Plymouth College of Art, July 2017, pp. 1-9.

[6] Asbjørn Sörensen C. A Material Framework for Product Design, 2018 (Faculty of Engineering, Lund University, Lund).

[7] Edvards J. and Steenfatt N. Jonas Edvards project Terrior 2016. Available: 
https://jonasedvard.dk/work/terroir/ [Accessed 2020-02-29]

[8] Carlsson H. Nya träfiberbaserade material = Nya formgivningsmöjligheter? 2019 (School of Arts and Communication, Malmö University, Sweden).

[9] Green Product Award 2020, Residue Chair Hanna Carlsson. Available: https://www.gpaward.com/en/produkte/Residue-Chair [Accessed 2020-02-29]

[10] Franklin, K.A. and Till, C.A., Radical Matter: rethinking materials for a sustainable future. 2018 (Thames \& Hudson, London).

[11] Gibbs G.R. Analysing qualitative data. 2008 (Sage).

[12] Gray T. How to do Your Case Study, A Guide for Students \& Researchers, 2011 (Sage)

[13] Halkier B. Methodological practicalities in analytical generalization. Qualitative Inquiry, 2011, 17(9), 787-797. 